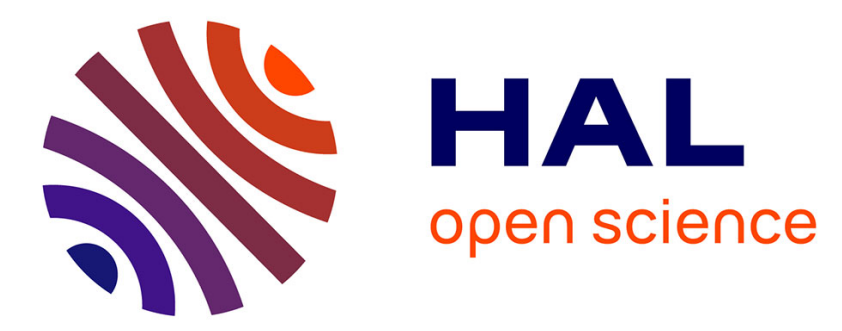

\title{
Evaluating Creativity Through the Degrees of Solidity of Its Assessment: A Relational Approach
}

Thomas Martine, François Cooren, Gerald Bartels

\section{To cite this version:}

Thomas Martine, François Cooren, Gerald Bartels. Evaluating Creativity Through the Degrees of Solidity of Its Assessment: A Relational Approach. The Journal of Creative Behavior, In press, 10.1002/jocb.219 . hal-01651192

HAL Id: hal-01651192

https://hal-audencia.archives-ouvertes.fr/hal-01651192

Submitted on 30 Nov 2017

HAL is a multi-disciplinary open access archive for the deposit and dissemination of scientific research documents, whether they are published or not. The documents may come from teaching and research institutions in France or abroad, or from public or private research centers.
L'archive ouverte pluridisciplinaire HAL, est destinée au dépôt et à la diffusion de documents scientifiques de niveau recherche, publiés ou non, émanant des établissements d'enseignement et de recherche français ou étrangers, des laboratoires publics ou privés. 


\title{
Evaluating Creativity Through the Degrees of Solidity of Its Assessment: A Relational Approach
}

\begin{abstract}
In this paper, we introduce a new approach to creativity assessment. Arguably, one of the main obstacles to creativity assessment is that creativity criteria are likely to change depending on what is assessed and who is making the assessment. We argue that we might be able to solve this problem by adopting a relational ontology, i.e., an ontology according to which beings of the world acquire their properties by relating to other beings. First, we present the main consequences of this ontological approach for creativity assessment: (a) Accounting for the creativity of a given object involves retracing the beings (including criteria) that relate it to its alleged creativity; (b) One can assess the creativity of this object by looking at the number of beings that substantiate this relation, i.e., by looking at what we call the "degree of solidity" of the relation; (c) One can thus account for the specificity of various forms of creativity and, at the same time, compare them in terms of solidity. Building on these ontological assumptions, we then present a new assessment technique, the Objection Counting Technique, before putting it to the test using an excerpt taken from a naturally occurring brainstorming session.
\end{abstract}

Keywords: creativity assessment, relational ontology, actor-network theory, interaction.

Arguably, one of the main obstacles to creativity assessment is what Theresa Amabile has called the criterion problem (Amabile, 1982, 1996; Hennessey \& Amabile, 2010). Simply put, this problem is that creativity criteria are likely to change depending on what is assessed and who is making the assessment. It is thus extremely difficult to compare creativity assessments to one another and, consequently, to progress in the detection of what facilitates or hinders creativity. In this paper, we will argue that the main obstacle to solving the criterion problem has been the ontological assumption on which the assessment techniques proposed so far have been based.

While divergent thinking tests (Runco, 1999; Torrance, 1974), historiometric studies (Simonton, 1980), self-assessment techniques (Kaufman, Plucker, \& Baer, 2008), and Consensual Assessment Techniques (CAT; Amabile, 1982, 1996; Baer, Kaufman, \& Gentile, 2004) certainly differ in many respects, they all seem to agree on one point, which is that creativity criteria must have a single point of origin: they must inhere either in the objects that are assessed or in the subjects who assess them. As we will show, this manner of settling the ontological status of creativity criteria leads to neglecting the particular contexts in which the creativity of something acquires its meaning and substance (Baer, 2010), and consequently, to hiding rather than revealing the elements that might serve to connect and compare various forms of creativity.

To try to solve the criterion problem, we propose to adopt a new approach to creativity assessment, one that is based on a relational ontology. This ontology, which can be traced back to pragmatism (James, 1912/ 1976), semiotics (Peirce, 1897), quantum physics (Bohr, 1963; Barad, 2007), and actor-network theory (Latour, 2005, 2013), assumes that beings of the world do not inherently possess their properties, but acquire them by relating to other beings. As we will show, this ontological assumption results in the following consequences for the study of creativity: (a) Accounting for the creativity of a given object (e.g., a person, a product or a process) involves retracing the beings (including criteria) that relate it to its alleged creativity; (b) One can assess the creativity of this object by looking at the number of beings that substantiate this relation, i.e., by looking at the "degree of solidity" of this relation; (c) One can thus account for the specificities of various forms of creativity (including their specific criteria) and, at the same time, compare them in terms of solidity. 
In what follows, we present a new assessment technique - the Objection Counting Technique (OCT) that rests on these assumptions and we put it to the test using an excerpt taken from a naturally occurring brainstorming session. While this technique remains largely developmental and speculative at this stage, we believe that it rests on solid theoretical and methodological foundations that could open new avenues in creativity assessment. One of the objectives of this paper is thus to encourage creativity researchers to appropriate this technique and help us further develop it.

\section{CREATIVITY ASSESSMENT AND THE CRITERION PROBLEM \\ THE CRITERION PROBLEM, DIVERGENT THINKING, AND HISTORIOMETRIC TESTS}

There seems to be a consensus in the literature on the basic defining traits of creativity, of which there are two: creativity requires both novelty and appropriateness (Hennessey \& Amabile, 2010). According to Runco and Jaeger (2012), the first author to use this definition was Stein in an article published in 1953. In his words, "the creative work is a novel work that is accepted as tenable or useful or satisfying by a group in some point in time" (p. 311). Since then, most definitions of creativity offered in the literature have been identical or very similar to that of Stein (see, for instance, Amabile, 1996; Bruner, 1962; Heinelt, 1974; Simonton, 1999).

However, so far it has proved impossible to reach a consensus as to the best way of refining this definition to obtain criteria that could be used to empirically assess creativity (Hennessey \& Amabile, 2010; Plucker \& Makel, 2010). Every operational criterion that has been offered invariably seems to disconnect the person or product being assessed from important aspects of its/him/her alleged novelty and/or appropriateness. One may think, for instance, of the widely used Torrance Tests of Creative Thinking (TTCT; Runco, 1999; Torrance, 1974). Such tests ask for multiple responses to either figural or verbal prompts (e.g., "think of as many ways to use a brick as possible"). Responses are then scored according to four specific criteria that are supposed to reflect their creativity: fluency, originality, flexibility, and elaboration.

Such tests are certainly an excellent way to assess individuals' relative ability to produce "divergent thinking." However, as several researchers repeatedly observed, it would be a mistake to consider them creativity tests (see notably Wallach, 1970; Runco, 2008). There are at least two reasons for this. First, it is problematic to operationalize originality (i.e., novelty) as unusualness. Arguably, a response to a problem may be extremely rare and still remain non-original if it has been offered even once before. Second, the only forms of appropriateness that the tests assess are the ones required for the tests. There is no guarantee that they are transferable to "real life," more complex forms of appropriateness.

Another example of the criterion problem may be found in the way Simonton (1980) proposed to assess the creativity of classical music themes. Simonton proceeded as follows: First, he determined the originality of more than 15,000 classical themes by analyzing the combination of the six first notes of each theme so as to calculate their relative degree of unusualness. Second, he determined the appropriateness of the themes (i.e., their fame in this case) by calculating "the frequency that each theme is performed, recorded, or otherwise cited" (Simonton, 1980, p. 210) in sources such as music appreciation texts, record-buying guides, concert guides, etc.

Simonton's technique is impressive notably because it relies on large sets of historically grounded data. But it is also open to criticisms. First, originality is once again operationalized as unusualness. Second, it is problematic to operationalize appropriateness as fame as there are certainly other ways for a classical theme to be judged appropriate. Third, and perhaps most importantly, the citations used by Simonton to assess the fame of the themes do not seem to refer to the themes specifically, but to entire musical pieces of which the themes are only a part (alongside rhythm, instruments, performers, etc.). It follows that what is assessed for originality (i.e., the six first notes of the themes) and what is assessed for appropriateness (i.e., the musical pieces that contain the themes) are only loosely connected in this technique.

\section{AMABILE'S SOLUTION: THE CONSENSUAL ASSESSMENT TECHNIQUE}

The seemingly intractable nature of the criterion problem has led Teresa Amabile $(1982,1996)$ to propose a radically different approach to creativity assessment. Whereas most previous approaches were based on the assumption that creativity can be assessed in an objective manner, Amabile's assumption is that creativity assessment is always "ultimately subjective."

However, according to Amabile, this does not necessarily mean that creativity lies beyond the reach of scientific investigation. As she explains, "creativity is something that people can recognize and often agree upon, even when they are not given a guiding definition.” (Amabile, 1996, p. 34). Therefore, although 
people assess creativity in a manner that is ultimately subjective, they nonetheless tend to arrive at similar results. This assumption, along with the idea that there are degrees of creativity, lies at the foundation of Amabile's CAT (Amabile, 1982, 1996).

The basic procedure of the CAT is to give participants a prompt or instruction for creating some kind of product and then have experts independently assess the creativity of those artifacts on a scale of 1.0-5.0. The expert judges are not asked to explain or defend their ratings in any way. They are simply asked to use their expert sense of what is creative in the domain in question to rate the creativity of the products in relation to one another. The degree of creativity of the assessed products then depends on the statistical reliability of the scores given by the experts.

The CAT proved to be greatly useful. Inter-rater reliabilities among expert judges were shown to be quite good across a wide range of domains (Amabile, 1996; Hennessey \& Amabile, 1999), which, in turn, allowed testing the influence of various social and environmental factors on creativity (Amabile, 1996). However, Amabile's approach to creativity assessment does not appear to be entirely satisfactory. Indeed, the creativity scores obtained using the CAT depend on narrowly defined contexts. That is, the score that a product receives in a given CAT study depends notably on the quality of the other products to which it happens to be compared in this particular study. Thus, a drawing that receives a score of 3 in one study, for instance, could receive a higher or lower score in another study, if the criteria used to select the drawings in this latter study were different from those used in the former one. In short, the creativity scores of different CAT studies cannot be compared to one another.

This means that it is impossible, using the CAT, to progressively accumulate creativity scores within a single creativity scale. This is a problem to the extent that knowing which products (or situations) are associated with the highest and the lowest levels of creativity would be key information to discovering what facilitates and what hinders creativity. Surely, there are good reasons to think that some forms of creativity may be incomparable to one another, but this incomparability ought to be tested. It should not be integral to the test apparatus itself.

\section{A RELATIONAL APPROACH TO CREATIVITY ASSESSMENT}

\section{THE “ONTOLOGY OF INHERENCE," ITS LIMITS, AND HOW TO OVERCOME THEM}

As already noted, the literature on creativity assessment has conceptualized creativity criteria in two opposing ways. On one side, divergent thinking tests (Runco, 1999; Torrance, 1974) and historiometric tests (Simonton, 1980) present their criteria as objective, i.e., as criteria that are supposed to belong to the assessed objects (whether they be individuals or products). On the other side, the CAT (Amabile, 1982, 1996) contends that creativity criteria are always "ultimately" subjective, i.e., criteria that belong to the subjects making the assessments.

It is noteworthy that these two opposing approaches actually share the same ontological premise, namely that creativity criteria must have a single point of origin: they must inhere either in the assessed objects or in the assessing subjects. In that respect, these approaches are both heirs of the same ontological tradition, which can be traced back to, most notably, René Descartes, Issac Newton, and Emmanuel Kant; a tradition that assumes that certain properties inherently belong to the subject, while others inherently belong to the object. We argue that this shared ontology of inherence results in a series of problematic consequences for creativity assessment.

First, this manner of settling the ontological status of creativity criteria leads to reducing or ignoring the particular contexts in which they acquire their meaning and substance, thus treating them as elementary units of analysis, that is, units that seem to inherently possess the qualities that define them. Second, given the large variety of criteria that can be used to assess creativity (Baer, 2010), the only way to proceed in a systematic manner is to ignore most of them, either by defining the criteria that should be used in a given assessment a priori, as in divergent thinking (Torrance, 1974) and historiometric tests (Simonton, 1980), or by calculating the statistical reliability of particular sets of subjective assessments, as in the CAT (Amabile, 1982, 1996). Third, the resulting assessment techniques either lose sight of important aspects of creativity, as in divergent thinking (Torrance, 1974) and historiometric tests (Simonton, 1980), or generate assessment aggregates that cannot be compared to one another, as in as in the CAT (Amabile, 1982, 1996).

We argue that we might be able to avoid this series of problems by adopting a different ontological approach. According to this approach, beings of the world do not inherently possess the qualities that define them, but acquire these qualities by relating to other beings. With regard to creativity (assessment), this means that the assessing subjects, the assessed objects, and an open-ended list of other beings (in particular 
creativity criteria) acquire their meaning and substance by relating to one another. This relational ontology results in the following consequences:

1 Accounting for the creativity of a given object (e.g., a person, a product, or a process) involves exploring the particular contexts in which this object is assessed so as to retrace the chain of beings (including criteria) that connect this object with its alleged creativity.

2 It becomes possible to compare the degree of creativity of various objects by looking at the number of beings (including criteria) that contribute to their relation with creativity; something we propose to call the "degree of solidity" of creativity assessments.

3 It thus becomes possible to account for the specificity of various contexts of assessment and, at the same time, to compare these particular contexts of assessment with one another. In other words, it becomes possible to extend various contexts of creativity evaluation by building bridges between them.

In the next section, we show, in further detail, how the relational ontology allows for creativity to be assessed through the degrees of solidity of its assessments.

\section{THE RELATIONAL ONTOLOGY OR HOW TO DETECT THE DEGREES OF SOLIDITY OF CREATIVITY ASSESSMENTS}

What does a relational ontology consist of? In keeping with the principle of radical empiricism, as proposed by William James (1912/1976), it amounts to asserting the reality of the relations we experience. James famously noted that, 'the relations that connect experiences must themselves be experienced relations, and any kind of relation experienced must be accounted as 'real' as anything else in the system" (p. 22). Although this point could, at first sight, appear negligible in the history of ideas, we believe that it amounts to questioning how subjectivity and objectivity have traditionally been conceived of, not only in philosophy, but also and especially in social sciences.

One of the most prominent advocates of this ontology is actor-network theory (ANT). This theory was first developed at the end of the 1970s by a few social researchers aiming to account for the work of scientists (Latour, 2005; Latour \& Woolgar, 1979). Whereas social theories of the time tended to reduce scientific activity to a few key explanations (such as individuals competition, social classes, or scientific rationality), ANT researchers proposed to account for all the actors that partake in this activity regardless of the way one may be tempted to categorize them a priori. That is, they proposed to approach every involved actor in exactly the same terms whether they be human, non-human, scientist, or lay-person (Callon, 1986). Over the years, this initial proposition developed into a theory that entirely rebuilds the ontology and epistemology of social sciences (Latour, 2005, 2013).

In keeping with relational ontology and ANT, we regard any entity as a collective action. That is, no entity inherently possesses any substance that can ensure its existence. To exist, an entity always needs to be performed by some other entities (Latour, 2005, 2013). In other words, the features that characterize an entity always need to be connected or related to one another by other entities. For instance, for an "original painting" to exist, a certain painting needs to be connected to originality. A simple way to make such a connection is, for instance, for a person - let us call her Ann - to state, in a conversation, "This painting is original."

In this case, (a) the statement makes the connection between the painting and originality, (b) Ann establishes connections between the words of her statement (i.e., she says them in a certain order), and (c) the alleged originality of the painting makes the connection between Ann and her statement (in the sense that it is supposed to be what makes her say what she says) (Cooren, 2010). Furthermore, we see that this analysis questions the a priori separation between subjective and objective statements, as the statement "This painting is original" can be seen not only as the expression of a certain subjectivity-it is indeed, at this point, Ann who apparently finds this painting original—but also the expression of a certain objectivity — the originality of this painting can be said to express itself through Ann's statement. ${ }^{1}$

\footnotetext{
We understand that this type of analysis may be shocking to someone adopting a humanist or social constructivist approach. According to this type of approach, originality cannot express itself through a statement, only humans (Ann, as it is) can. However, from a relational perspective, expressing itself is a basic attribute of all beings whether they are people, ideas, buildings, emotions, or planets. All these beings express themselves in the sense that they all make a difference in specific situations, which of course does not mean that they express themselves in the same manner (i.e., that they make the same difference). In this perspective, accounting for the originality of something amounts precisely to showing the particular way the originality of this thing expresses itself, that is, the specific network of beings (including people and statements) that allows it to make a difference in a given situation.
} 
This is as far as the analysis can go in this case, given the data available. However, this limitation is only of an empirical order. Indeed, from an Actor-Network perspective, any connection/relation can theoretically be broken down into smaller connections involving new entities. The problem, explains Latour (2005, 2013), is that once a network is set up, it is impossible to an outside observer to detect the entities that partake in its establishment. Everything happens as if the elements of the ready-made network really were all that constitute the network. Thus, in the example above, everything happens as if Ann and her statement really were all that makes the painting original (or, conversely, as if the originality of the painting really was directly speaking through Ann and her statement).

Therefore, to study a certain connection or relation, one must always start by looking for ways to interrupt it. Only then, argues Latour $(2005,2013)$, shall one see what the connection/relation comprises. Still using the same example, a simple way for an observer to interrupt the connection between the painting and originality would be to ask Ann why the painting is original. Ann might then answer, for instance, "It is original because it uses a color that has never been used before." Of course, one could retort that such an answer does not make much of a difference since the observer still does not know whether what Ann says is true. However, from an Actor-Network perspective, this answer matters because it changes the very nature of the connection between the painting and its alleged originality. This connection is no longer made only of a statement, Ann, a painting and the notion of originality. It is also (supposed to be) made of the particular color used in the painting as well as the set of colors used in all the paintings made before this one.

Furthermore, this change makes a difference in the sense that it invites the observer to redirect her inquiry toward new elements (i.e., those related to the color of the painting). In other words, regardless of what the observer may be able to uncover at the end of her inquiry, at this precise moment, Ann's new argument objects to the observer's attempt to disconnect the painting from its alleged originality. Put another way, at this precise point of the discussion, the connection between the painting and its supposed originality has gained one additional degree of solidity.

In a typical relational move, we see that our analysis focuses on the connections/relations and their solidity or absence thereof. A connection/relation is all the more solid in that it resists attempts to question its existence. In our illustration, the connection between the painting and its alleged originality is supposed to not only express itself through the initial statement made by Ann, but also through her response to an objection, a response that consists of highlighting a specific aspect of the painting, i.e., its color. Relationally speaking, we could then note that the originality of the painting not only expresses itself through what Ann was saying about its alleged originality, but also through the color she is now highlighting, which adds to the solidity of this connection, that is, the connection between this painting and what could be called its originality. ${ }^{2}$

As we can see, solidity is conceptualized here as a form of recalcitrance (Burke, 1935/1984; Prelli, Anderson, \& Althouse, 2011) that can be assessed in terms of degrees. The degree of solidity of a connection depends on the number of elements that object to its destruction or, conversely, on its capacity to overcome or resist objections to its existence. Thus, in our example, we could imagine that the observer keeps questioning the connection/relation between the painting and originality using all sorts of arguments. Every time the speaker would be able to respond to one of these arguments, the connection between the painting and originality would gain one additional degree of solidity.

It is important at this point to note that this measure of solidity is always also a measure of existence. That is, there is not the solidity of the assessment on the one hand and the existence of the assessed thing on the other. These two aspects always emerge together. In our example, the things that object to separating the painting from originality are both what maintains the entity "the original painting" in existence and what gives solidity to the assessment that says, "This painting is original." In this sense, questions of ontology are always also questions of epistemology and vice versa. ${ }^{3}$ This is important as it explains why the degree of solidity of creativity assessment can be regarded as a measure of creativity.

\footnotetext{
2 Although we cannot develop this point further here, it should be clear that our relational ontology owes a lot to Charles Sanders Peirce, the founder of pragmatism, semiotics, but also the logic of relatives. Peirce helps us understand that we are not the sole origin of our interpretations or reactions, but that they also depend on what our environment tells us, whether iconically, indexically, or symbolically. In other words, Peirce's pragmatism and semiotics imply a relational ontology. For more details, see Cooren (2016).

3 About the inseparability of ontology and epistemology, see Latour (2005, 2013), Barad (2007), and Peirce (1897).
} 
What now remains to be seen is how we can translate this ontological and epistemological framework into an operational technique for capturing, analyzing, and assessing the degrees of solidity of connections between certain beings and their alleged creativity.

\section{THE OBJECTION COUNTING TECHNIQUE ACCESSING CREATIVITY THROUGH CONVERSATIONS}

How can we observe the creative nature of something (e.g., a person, a product, or a process)? That is, how can we access the various elements that partake in the connection between this thing and its alleged creativity? As we saw, an answer based on a relational ontology is: by finding as many means of interrupting this connection as necessary. So, how do we do this?

We believe an interesting starting point is to recognize that such interruptions occur naturally every time two or more persons collectively seek to produce something creative. Indeed, we may assume that in such circumstances, people need to do the following:

1 They need to communicate what they believe is creative. That is, they need to break down what they believe to be creative into elements (such as words or gestures) that are understandable for the other participants.

2 They need to negotiate what they believe is creative. That is, they need to undo parts of their propositions either to incorporate propositions made by other participants or to add arguments to exclude other participants' propositions.

Thus, to access the creative nature of something, we propose (a) to video record any collective event that has, as an explicit goal, to produce something creative (e.g., a brainstorming meeting), (b) to use the video recording to retrace the elements that the participants had to go through to connect a certain thing (may this be only an idea) with its alleged creativity.

\section{DETECTING CONNECTIONS WITH CREATIVITY}

How do we recognize a connection between something and creativity? In other words, when can we say that a link/relation/connection is established between a thing and both novelty and appropriateness? What are the minimum requirements for this to happen? We believe such requirements can be inferred from common definitions of "novel" and "appropriate".

For instance, the Merriam-Webster dictionary defines "novel" (n.d.) as what is "new and not resembling something formerly known or used." From this definition we can infer that the connection of something with novelty requires at least the following elements:

- An association of at least two things;

- Two periods of time ( $t 1$ and $t 2$ ) such as $t 1$ ends when $t 2$ begins;

- The assertion that the association is what marks the end of $t 1$ (and therefore also the beginning of $t 2$ ).

The Merriam-Webster dictionary defines "appropriate" (n.d.) as what is "right or suited for some purpose or situation". From this definition we can infer that the connection of something with appropriateness requires at least the following elements:

- A thing;

- A definition of what is appropriate in a certain situation;

- The assertion that the thing fits this definition of what is appropriate.

We believe these minimum requirements can be used as a guideline to detect most links/relations/connections with creativity, including those where the ideas of novelty and appropriateness are expressed implicitly. Let us take, for instance, the following fictional situation. Two art lovers (Ann and Bob) roam the corridors of an art gallery. Suddenly, Ann points at an impressionist painting and says:

See this high key of color. You did not see that in the early 19th century. And it so perfectly captures the light of this precise moment of the day!

In this case, although Ann does not use the terms "novel" and "appropriate," we can detect that the painting she talks about connects with both novelty and appropriateness, as shown in Tables 1 and 2, and, consequently, with creativity (see also Figure 1 below). 
TABLE 1. Connections Between the Painting and Novelty

\begin{tabular}{l} 
Novelty requirements \\
\hline $\begin{array}{l}\text { An association of at least two things A painting (1) with high key of color (2) } \\
\text { Two periods of time such as tl ends }\end{array}$ \\
$\begin{array}{l}\text { The painting is implicitly situated in the time that comes immediately } \\
\text { after "the early 19th century" }\end{array}$ \\
$\begin{array}{l}\text { The assertion that the association is } \\
\text { The painting is implicitly presented as what marks the end of "the } \\
\text { early 19th century" }\end{array}$
\end{tabular}

TABLE 2. Connections Between the Painting and Appropriateness

\begin{tabular}{ll}
\hline Appropriateness requirements & \multicolumn{1}{c}{ Corresponding features } \\
\hline A thing & A painting \\
A definition of what is appropriate in this situation & Capturing the light of a precise moment \\
$\begin{array}{l}\text { The assertion that the thing fits with this definition } \\
\text { of what is appropriate }\end{array}$ & $\begin{array}{l}\text { The painting is presented as capturing this kind of } \\
\text { light }\end{array}$ \\
\hline
\end{tabular}

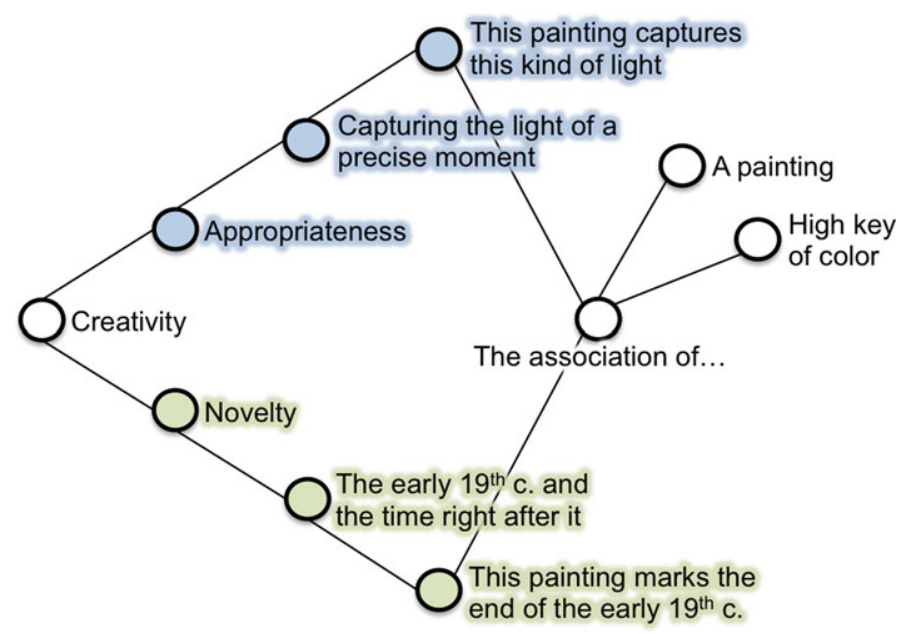

FIGURE 1. Connection of the painting with creativity. This figure represents the network of elements that allows "the painting with high key of color" to connect with both appropriateness (in blue) and novelty (in yellow), and thereby with creativity. This network simply meets the minimum requirements for creativity to be detected. Therefore the connection with creativity has level-1 solidity.

It is noteworthy that the criteria of novelty and appropriateness are only intended here to distinguish between situations where there is creativity and situations where there is none. They should not be regarded as a way to reduce creativity to these two terms. Indeed, as the Merriam-Webster dictionary clearly indicates, these terms cannot be meaningfully used outside of specific contexts: what is "novel" always involves "something formerly known or used" while what is "appropriate" always involves "some purpose or situation." It follows that accounting for the novel and appropriate character of something implies to detect the particular criteria that allow connecting this thing with the notions of novelty and appropriateness in a specific context. There are thus countless ways of being novel and appropriate just as there are countless ways of being creative. 


\section{DETECTING FLUCTUATIONS IN TERMS OF DEGREES OF SOLIDITY}

Let us now see how we can detect how a connection between something and creativity may fluctuate in terms of degrees of solidity. Let us say that a connection between something and creativity has level-1 solidity, when the network of elements that constitutes it simply meets the minimum requirements for creativity to be detected. Such a connection has indeed little solidity to the extent that we do not know what substantiates the elements that partake in it. In other words, we do not know what constitutes the elements that constitute it (see Figure 1 above).

However, such a connection has just enough solidity to allow an inquiry about the elements that constitute it to start. Indeed, once links have been established between a certain thing and (the notions of) novelty and appropriateness, it becomes possible to object to these links and see if they resist. For instance, in the impressionist painting case, Bob could object to the following links between:

- The painting and appropriateness by saying that what really matters for a painting is having a balanced composition (and not capturing the light of a particular moment).

- The painting and novelty by saying that this high key of color could be seen in some paintings of the early 19th century, as well (see Figure 2 below).

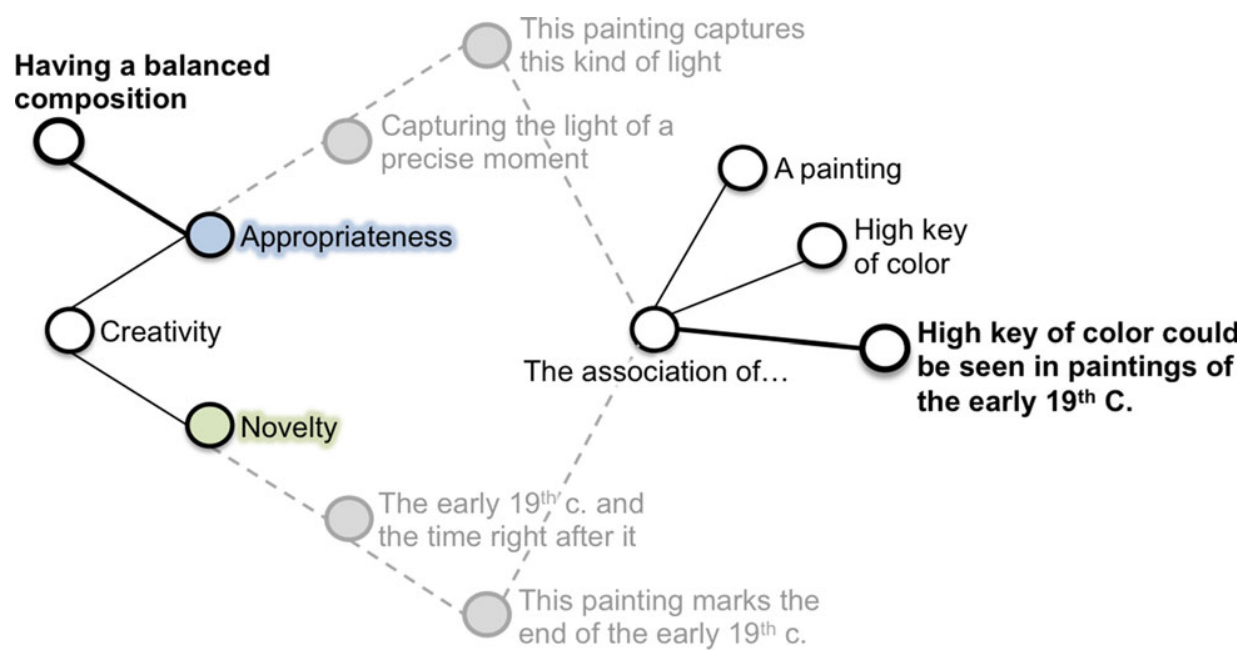

FIGURE 2. Disconnection between the painting and creativity. This figure presents Bob's objections under the form of a network. The bold solid lines represent the alternative links he established. The dotted lines represent the links that dissolve as a result of these alternative links. As we can see, Bob's objections cause the connection between the painting and creativity to dematerialize.

At this point, the only way for Ann to sustain the connection between the painting and creativity is to object to these objections, that is, to establish new links that contradict those established by Bob. For instance, Ann could object to the links between:

- Appropriateness and composition (as the sole criterion of appropriateness) by saying that capturing the light of a particular moment also matters for it allows for the representation of the fleeting nature of existence.

- The early 19th century and high key of color by saying that the pigments necessary to produce such key of color were not commercially available before the mid-19th century.

These new elements strengthen the solidity of the connection between the painting and creativity in the sense that they object to Bob's attempt to undo this connection. Let us call such elements Solidifying Features of Creativity (SFC). We contend that the level of solidity of a connection between something and creativity corresponds to the total number of SFCs that are added to the basic elements of the connection. As it is, the 
connection between the impressionist painting and creativity, which takes shape through Ann's last turn of speech, shows 2 SFCs. Theses add to a connection with level-1 solidity, resulting in a connection with level3 solidity (see Figure 3 below).

It is noteworthy at this point that what we call a "counter-objection" (or an "answer to an objection") does not necessarily involve two persons, one raising an objection and the other responding to it, as it is the case in the example above. Both the objection(s) and the counter-objection(s) may be found in the words, gestures, and actions of a single actor (human or non-human). This is, for instance, what we all tend to do when we try to build a convincing case: we try to address in advance the objections that someone (or something) might have with regard to our arguments. It follows that detecting the degree of solidity of a connection involves paying particular attention to the details of what (human and nonhuman) actors say or do.

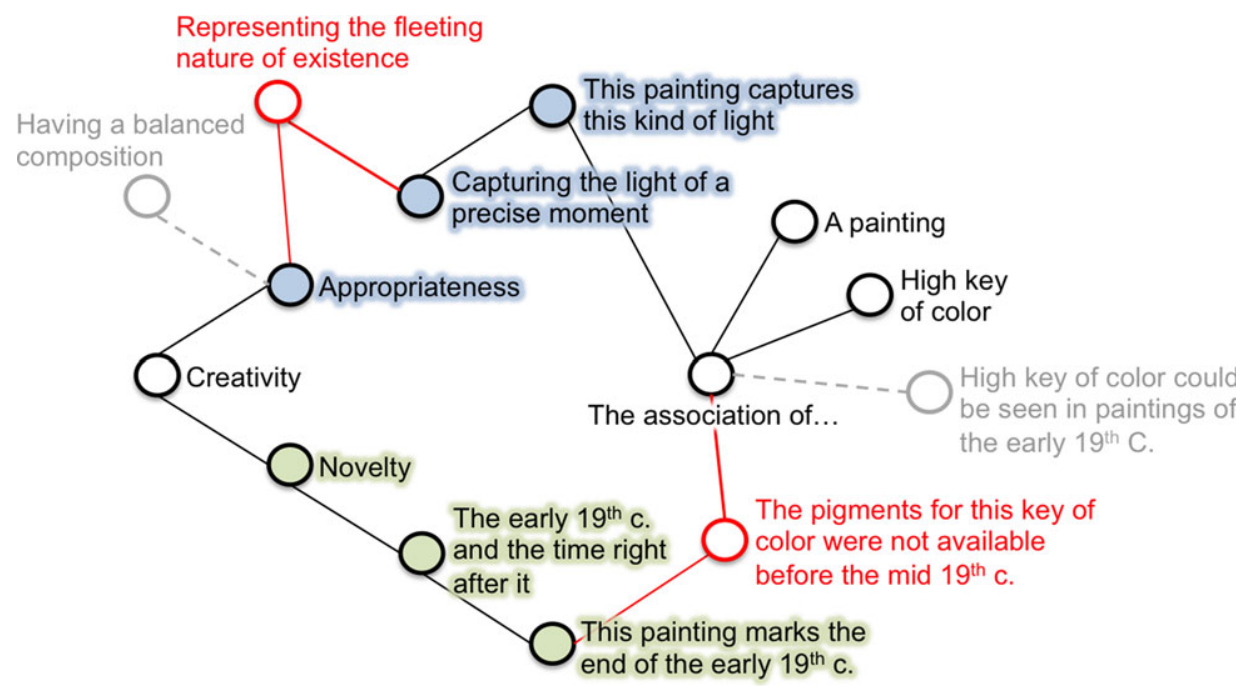

FIGURE 3. Reconnection of the painting with creativity. This figure presents Ann's counter-objections under the form of a network. The solid lines in red represent the alternative links she established. The dotted lines represent the links that dissolve as a result of these alternative links. As we can see, Ann's counterobjections cause the connection between the painting and creativity to rematerialize.

\section{CASE STUDY: BRAINSTORMING AT THE C CENTER}

As part of a research project on creativity funded by the Canadian Social Sciences and Humanities Research Council, the authors studied the activities of the C Center (the name has been changed). Located in North America, this center describes itself as a "creativity incubator." It offers residencies, workshops, and other forms of support to artists in many fields, as well as to organizations' leaders in both profit and non-profit sectors. It also works as a conference center. Between August 2013 and March 2014, the authors regularly went to the C Center to observe and videotape potentially creative workshops involving various organizations' leaders. The discussion analyzed below is an excerpt from a 3-day workshop held in September 2013. In comparison to the other workshops observed, this one was somewhat special to the extent that it focused on the C Center itself (and not on a client organization).

Its purpose was to reflect on new ways of operating the Center's leadership activities (i.e., skill-building activities offered to organizations' leaders). The conversation below is an excerpt from the third day of the workshop. Present are John, director of leadership activities, Mia and Marty, both consultants in organizational change, Gail and Mike, both entrepreneurs in the Internet sector, as well as two of the authors, Gary and Tom (all names have been changed). In the hour preceding the excerpt below, the conversation progressively focused on the C Center's values. The participants' rationale can be summarized as follows: (a) To 
find appropriate new ideas for the leadership activities, they have to precisely identify the core values of the Center; (b) To identify these values they have to find "narratives" that are emblematic of the Center-something like "war stories" or "myths."

Thus, at this point in their conversation, the participants have started to elaborate a specific definition of what is novel and appropriate: Something appropriate should be connected to value(s) embodied in the Center's mythology. Something novel should be different from current leadership activities. Let us now see how the participants managed to connect ideas to this basic definition of creativity and then augment the degree of solidity of this connection (see the verbatim excerpt below).

John: There is a great story about (.) it's a true story (.) we had the pig people coming in January Gail: What who?=

John: =The pig people? The swine producers of the region and there's about 400 of them (1.0) and the whole centre went on lock down this was our biggest conference client and it took over the whole centre all the space (.) and they had their own signage which were shaped like pigs and the rest of the centre was told $<$ do not fuck $>$ with the pig people they are too important don't mess with pig people (0.2) we had a music workshop in and the music director of the time decided that he was gonna declare war on the pig people $(0.5)$ and so he got his musicians to go and steal everyone of the pig signs they could find and bring it to him as an offering ((laughing)) $\uparrow$ I don't know if this is true or not it might be apocryphal $\downarrow$ but it became a bit of a legend (.) So the jazz musicians sometimes in June they're like when are the pig people here? ((several persons starts laughing)) I am like IANUARY $\underline{\mathrm{OH}}$ I wanted one of the pig signs (.) It's like a part of the legend of the C Centre

John: I think it is a story that gets people to talk about $(0.5)$ what values are imbedded in it

Mia: And I think what it also talks about is communication (that) even though the pig farmers thought they were not gonna communicate (.) with (.) the centre (.) the centre communicated with them

John: ${ }^{\circ} Y e a{ }^{\circ}{ }^{Y} \mathrm{EAH}$ it's true (.) whether they wanted it or not >and I don't think that it was that they were against it I think they were just insulated and protected from the rest of it (.) and the musicians decided to $=$

Mia: =Break down the boundary so they broke down the boundary

John: And these weren't rock musicians (0.5) these were the classical musicians [((laughing))

Gail:

[Animal farm all over again

Mia: But what I like about that is because it's showing a part of artists also having a deep sense of humor and fun which if you cannot have that you cannot experiment like (.) if you cannot laugh at yourself or can't have that sense of lightness of being (.) which is missing in a lot of places in the moment

Gail: $\quad$ =Yeah=

Mia: = = They sit in the room you go like everyone did you forget the child inside? Like why are you here? You're definitely not having fun you're not (in any hope of) having fun' like ((shaking her head)) (0.5) like are you doing this when you're $\underline{60}$ ? You gonna sit next to the river ${ }^{\circ}$ and maybe find that (.) you know ${ }^{\circ}($.$) and this is yes that lightness$

Gail: So what would it look like if you created (2.0) contrived opportunities (.) for childlike behavior? So for example

John: Would look like one of our programs [((laughing))

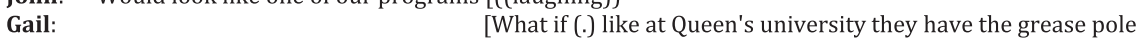
(0.5) so they create an opportunity for people to be stupid

John: Have you done the grease pole?

Gail: $\quad$ No I didn't go to Queen's

John: Ok

Gail: But [my friends

John: [Cause it's it's dehumanizing in a really really deep way ((laughs briefly))

Gail: Sure but sure but it's also (1.0) a rite [of passage for some people

John: [Y Yes

Gail: It's uh:: [it's a

John: $\quad$ You get filthy=

Gail: =You do or it can be like at MIT where the first year engineering students have to break the ru::les and the year that I was there they took the dean's car and broke it apart and stuck it up on the roof of one of the computer science ( ) and reassembled it=

John: =That's awesome

Gail: So what would it look like if the C Center if aside from the trail walks and the nature and all that stuff (.) you actually created opportunities for people to misbehave? $\uparrow$ YOU DON’T actually force it people John: would choose whether or not they want to take that opportunity [like uh

Gail: $\quad$ Like the jazz musicians or the (0.5)

[You could encourage it

John: Classical musicians [((laughing)) 


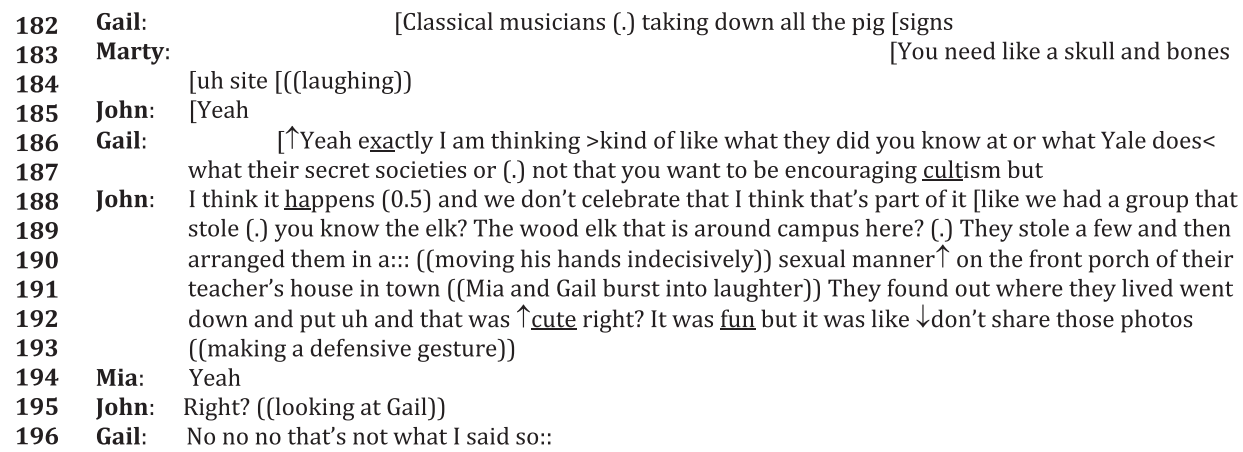

At the beginning of this excerpt (1. 110-140), we see John telling a story that is supposed to illustrate the kind of narrative the participants are looking for at this point in their conversation. As he says, the pig people story became "a part of the legend of the C Center" (1.121) in the sense that it is "a story that gets people to talk about what values are embedded in it" (1. 140). In lines 141-157 we then see Mia trying to unpack the values embedded in the story. She sees the "pig people" story first as an illustration of the Center's power to communicate with people even when people do not want to communicate with it (1. 141142), and then as an instance of a group breaking down the boundary that separates it from another (1. 146), and finally as an example of the "sense of humor" and "lightness" that is necessary to be able to "experiment" (1. 149-151); something, she adds, that contrasts with her experience with "big corporates" where everyone seems to have forgotten "the child inside" (1. 151-157).

Of note, no connection is established with creativity at this point. The various values offered by Mia might be considered appropriate here to the extent that they are all presented as embedded in a legend of the Center. However, they could hardly be considered novel to the extent that nothing at this stage indicates that they are any different from those embedded in the current leadership activities. In short, the connection between her proposition and creativity seems to have level 0 solidity at this point $(\mathrm{Sol}=0)$. However, this changes the moment Gail makes the following proposition: "what would it look like if you created contrived opportunities for childlike behavior?" (1. 158). This idea is presented as appropriate to the extent that it directly refers to one of the values Mia saw in the pig people story (i.e., being able not to "forget the child inside" (1. 154)). However, and this is the difference, it is also presented as something (potentially) novel.

Indeed, by asking "what would it look like if. . ?", Gail invites the participants to envision something hypothetical; something she considers as not already existing (in the Center). This connection with novelty might be quite fragile since we do not know much about what substantiates it at this point, but it nonetheless exists to the extent that it is detectable. That is, what Gail is saying here effectively objects to keeping her proposition separate from questions of novelty. Therefore at this point, the creativity of her proposition materializes with level-1 solidity $(\mathrm{Sol}=1)$.

However, this also means that the creative nature of her proposition now has just enough solidity to be objected to or called into question. As we see, this is precisely what happens when John answers Gail: "Would look like one of our programs" (1. 160). In other words, no need to envision anything hypothetical here, for this idea already exists in the center's business as usual. Thus, the creativity of Gail's proposition now dematerializes to the extent that it is no longer connected with novelty $(\mathrm{Sol}=0)$. Through John's objection, the (solidity of the) creative character of what Gail proposes is questioned.

But Gail does not give up. As she says: "What if, like at Queen's University they have the grease pole so they create an opportunity for people to be stupid" (1. 161-162). Coming right after John's objection, this reference to the grease pole can be understood as a way for Gail to defend the novelty of her idea. Creating opportunities for childlike behavior, she seems to say, could be different from what already exists at the Center if it means doing something like the grease pole. Thus, not only does Gail reconnect her proposition with novelty here, but she also gives it one additional degree of solidity to the extent that her reference to the grease pole is supposed to object to John's objection ( $\mathrm{Sol}=2$ ).

We then see John voicing another objection focusing this time on the appropriateness of Gail's proposition. He says that the grease pole is "dehumanizing in a really really deep way" (1. 167). Then, when Gail 
retorts that "it's also a rite of passage for some people" (1. 168), he simply adds: "You get filthy" (1. 171), thus suggesting that this "rite of passage" only consists of this (getting filthy). What John does here is introduce a new criterion of appropriateness. Something appropriate no longer only needs to feature a value embedded in one of the Center's legends (e.g., childish "lightness"). It also needs to be respectful of human dignity. According to John, this is precisely what is missing in Gail's proposition, which therefore is once again disconnected from its creative character $(\mathrm{Sol}=0)$.

But Gail still does not give up. She then takes the example of the first year engineering students at MIT (1. 172-174). With this new example, Gail is killing two birds with one stone. Indeed, by presenting the MIT student action as an alternative to the grease pole ("or it can be..."), she defends both the novelty and the appropriateness of her proposition. On the one hand, she creates equivalence between the two examples, thus suggesting that both are different from current leadership activities.

On the other hand, she introduces a difference, thus suggesting that, in contrast to the grease pole, the MIT student action respects human dignity. Creating opportunities for childlike behavior, she seems to say, can be respectful of people's dignity. Thus, by objecting to John's two previous objections, this new example gives two additional degrees of solidity to the connection linking Gail's (initial) proposition and its creativity $($ Sol $=3)$.

Furthermore, Gail quickly finds another way to answer John's concern for people's dignity. When creating "opportunities for people to misbehave" (1. 177), she says:

YOU DON'T actually force it, people would choose whether or not they want to take that opportunity.

(1. 177-178)

Whereas her argument so far was merely that childish behaviors do not necessarily affect people's dignity (e.g., in the MIT student case), she now advocates taking a more active approach (i.e., making sure people have the choice not to participate). Thus, by objecting to John's concern about dignity in a different way, this new argument gives another degree of solidity to the connection between her proposition and its creative character $(\mathrm{Sol}=4)$.

However, Gail then appears to run into trouble. Picking up on Marty's suggestion to have "a skull and bones site" (1. 183-184), she suddenly realizes the problem with it: Yale's secret society, Skull and Bones, is associated with cultism, which might pose another problem of appropriateness. We then see John seizing the opportunity to drive the point home. The wood elk story he tells at the end of the excerpt (1. 188-193) is presented as an illustration of the intrinsic link that exists, for him, between childlike behavior ("cute" and "fun", 1. 192) and risks for people's dignity, evidenced, in the present case, by the existence of photos that must not be shared (192-193) and, more broadly, by the idea that certain things "happen" but "we don't celebrate" them (1. 188). This link results, once again, in interrupting the connection between Gail's idea and its appropriate and, therefore, creative character $(\mathrm{Sol}=0)$.

Figure 4 below shows how the connection between Gail's idea and creativity fluctuates in terms of degrees of solidity over the course of this sequence.

\section{DISCUSSION \\ A NEW APPROACH TO THE CRITERION PROBLEM}

Hitherto, there were at least two main ways to deal with the criterion problem (i.e., the fact that most creativity criteria change depending on what is assessed and who is making the assessment). The first one was to substitute the defining traits of creativity (i.e., novelty and appropriateness) with more operational criteria such as "unusualness" (e.g., Runco, 1999; Simonton, 1980; Torrance, 1974) or "fame" (e.g., Simonton, 1980). The problem with such substitutions is that they tend de facto to exclude all definitions of creativity that cannot be reduced to such criteria (but fit with the generally agreed upon, though vague, criteria of novelty and appropriateness).

The other way to deal with the criterion problem was to bypass it entirely. This is the way chosen by the CAT (Amabile, 1982, 1996; Baer et al., 2004). By calculating the statistical reliability of the creativity scores that experts attribute to particular sets of creative products, this technique makes it unnecessary to know anything about the criteria used to assess the products. However, as we saw, this technique involves creating assessments aggregates that cannot be compared to one another, thus making it difficult to progress in the identification of what hinders or facilitates creativity. 


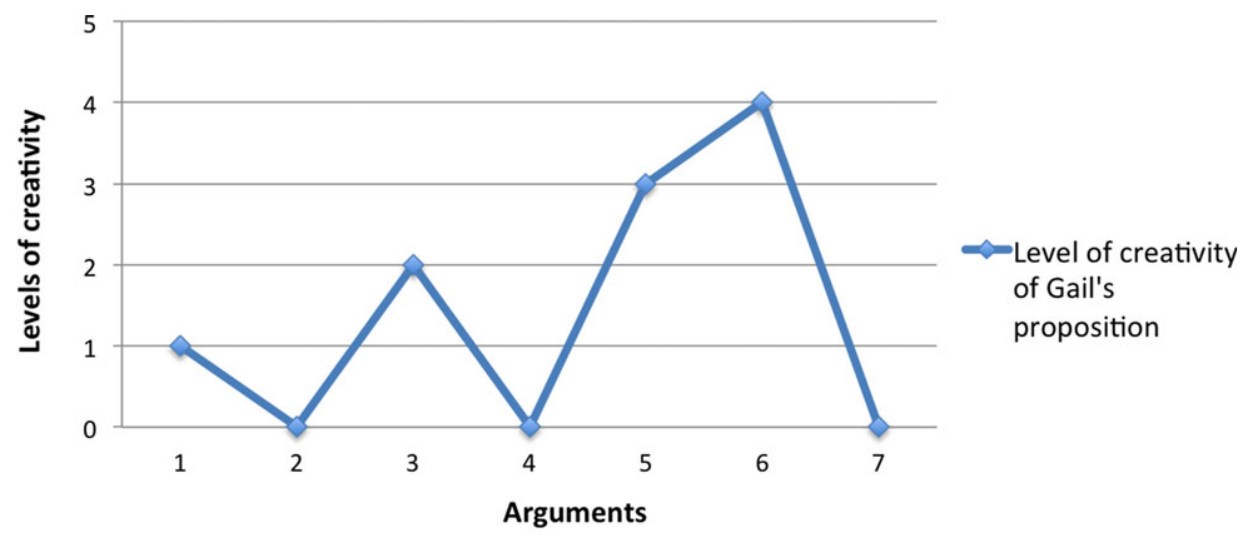

\section{\#1: (Gail) 'What would it look like if you created contrived opportunities for childlike behavior?'}

\section{\#2: (John) 'Would look like one of our programs'}

\#3: (Gail) 'What if, like at Queen's University they have the grease pole...?' \#4: (John) 'It's dehumanizing in a really really deep way'

\begin{abstract}
\#5: (Gail) 'Or it can be like at MIT where the first year engineering students have to break the rules...'

\#6: (Gail) 'People would choose whether or not they want to take that opportunity'

\#7: (John) The Center needs guarantees that people's dignity will be respected (the wood elk story)
\end{abstract}

FIGURE 4. Degree of creativity of Gail's proposition during the episode.

In short, it seems the ways to deal with the criterion problem were either to arbitrarily define the creativity criteria or to treat the issue as a black box. This being said, these two diametrically opposite limitations were useful to the extent that they marked the path of new approach to the criterion problem: One had to find an assessment technique that was at once flexible enough to embrace the continuously changing set of creativity criteria and sensitive enough to register what is specific about each of them. We believe the OCT is such a technique.

The OCT is flexible enough if we accept that any relation between something (e.g., an idea, a product, a person) and its alleged creativity fluctuates in terms of solidity. This is our basic ontological assumption. But now, is this technique also sensitive enough? Here, several objections might be raised.

First, one could observe that the OCT is based not only on the degree of solidity of relations, but also on the criteria of novelty and appropriateness, criteria that might not always fit the way people actually define creativity in interaction. While we cannot completely rule out such a possibility, we believe that it is very unlikely for two reasons. First, it is hard to conceive of a definition of creativity that would not include any reference to novelty or originality (it would seem to defy the core of what creativity is about). Second, as already noted, the notion of appropriateness is by definition extremely context-dependent, which means that it can take an endless number of forms. In fact, if someone defined creativity only and exclusively as the production of something original or new, this very definition could be understood as a criterion of appropriateness in the sense that it would present the use of any other criterion as inappropriate.

Second, someone could object that the OCT seems to treat any argument or element that leads to reinforcing the creative character of something as having the same value, thus failing to account for the difference of weight or influence that may exist between them. It is true that the illustrations we used in this article do not show how the OCT might be able to account for such differences. This does not mean, however, that it is unable to do so. In keeping with the relational ontology, if arguments or elements have greater value than others, this means that there exist specific relations through which this difference in value 
can be experienced. For instance, if during a debate an argument is met with marks of agreement, enthusiasm, or commitment, whereas other arguments are not, these marks substantiate the relative greater value of this argument. They show, each in their own way, that this argument has overcome the silent objection of indifference and they must therefore be taken into account by the OCT.

Finally, while one may have the impression that the OCT disregards power relations in interaction, we believe this impression is due to the examples and data analyzed in this article rather than to the OCT itself. Here again, if differences in status, for instance, play a role in the way the creative character of something is evaluated, this means that there exist specific relations through which they can be experienced. For instance, if during a team meeting, the official team leader endorses (or dismisses) a particular idea that is then no longer debated, the very fact it is no longer debated could be understood as the materialization of the team leader's formal authority, an authority that would then be an integral part of the connection between the idea and its alleged creativity (or lack thereof) and, consequently, something that should be taken into account by the OCT.

This being said, the OCT is still at a development stage and it is more than likely that it will have to be further refined in the future to accurately account for the various ways creativity manifests itself. As it stands, for instance, the OCT might overly rely on explicit objections and counter-objections to detect the degree of solidity of connections with creativity, which limits its ability to account for more implicit connections. Therefore, we would like to encourage creativity researchers to help us to further develop the OCT by integrating it into their own work. For instance, it would be very useful to use it in combination with the CAT for at least two reasons. First, the CAT could be used to corroborate the results produced with the OCT; that is, to verify whether the solidity of the implicit creativity assessments that people make about something is reflected in the way people tend to individually rate the creativity of this thing. Second, assuming that there is indeed a relation between these two types of assessment, the OCT could be regarded as a way to reveal the various elements that explain (and constitute) the creativity differences measured by the CAT.

IS OUR TECHNIQUE REALLY TOO COSTLY?

Now, there is one last objection that we need to address, which is that the OCT might be too costly. For sure, to account for the degree of solidity of a connection with creativity, one must do many things: Finding an event where people are likely to discuss the creative nature of something, getting these people to accept to be video-recorded, detecting the moments where they actually discuss the creativity of something in the recordings, rigorously transcribing these moments, deciphering the arguments and counterarguments that are exchanged in these moments, and eventually calculating the degree of solidity of the connection(s) that is (or are) established and maintained during this event.

And of course, once all this is done, we most likely have the degree of solidity of only one connection with creativity. That is, we would have to do the work all over again just to be able to make one comparison. The cost of this technique is then certainly much higher than that of the CAT, for instance, which has already been critiqued for its high cost (Amabile, 1996; Kaufman, Lee, Baer, \& Lee, 2007). However, we believe the cost of the OCT should be assessed in relation to the benefits it might bring.

We would like to highlight two of these benefits here. First, as we mentioned, our technique seems to be the first that allows assessing virtually any form of creativity within a single scale. This means that virtually every creativity score acquired using this technique can be compared with another. It thus becomes possible to compare, for instance, products concerning arts, management, engineering, and science, or products that involved 2, 10, or 30 people. This is a great advantage over the CAT, most notably, whose creativity scores, as we saw, are incomparable across experiments. This means that our technique might have a great potential for accumulating research results over the long term.

Speaking of future research, the second important merit of our technique might be that it relies on extremely rich data, namely the recordings of the interactions during which the creativity of something or someone is collectively assessed. This is important for, as various communication researchers have shown over the past 10 years, creativity is far from being the only thing that manifests itself over the course of communicational interactions. Things as various as rules, technologies, emotions, principles, ideas, or even architectural elements have been shown not only to act in such interactions, but also to act with various degrees of authority or force (Bencherki \& Cooren, 2011; Cooren \& Sandler, 2014; Kuhn \& Burk, 2014; Martine, Cooren, Bénel, \& Zacklad, 2016; Vasquez, 2013). 
Thus, as we will accumulate discussions about the creative nature of things, we may be able to uncover correlations between the level of solidity of certain connections with creativity and the level of authority (or force) of certain rules, technologies, emotions, etc. These are precisely the correlations that we are currently working on detecting.

\section{REFERENCES}

Amabile, T.M. (1982). Social psychology of creativity: A consensual assessment technique. Journal of Personality and Social Psychology, 43, 997-1013.

Amabile, T.M. (1996). Creativity in context: Update to the social psychology of creativity. Boulder, CO: Westview.

Baer, J. (2010). Is creativity domain specific? In J.C. Kaufman \& R.J. Sternberg (Eds.), Cambridge handbook of creativity (pp. 32141). Cambridge, UK: Cambridge University Press.

Barad, K. (2007). Meeting the Universe Halfway: Quantum physics and the entanglement of matter and meaning. Durham, NC: Duke University Press.

Baer, J., Kaufman, J.C., \& Gentile, C.A. (2004). Extension of the consensual assessment technique to nonparallel creative products. Creativity Research Journal, 16, 113-117.

Bencherki, N., \& Cooren, F. (2011). Having to be: The possessive constitution of organization. Human Relations, 64, $1579-1607$.

Bohr, N.H.D. (1963). The philosophical writings of Niels Bohr. Essays, 1933-1957, on atomic physics and human knowledge (Vol. 2). Woodbridge, CT: Ox Bow Press.

Bruner, J.S. (1962). The conditions of creativity. In H. Gruber, G. Terrell \& M. Wertheimer (Eds.), Contemporary approaches to creative thinking (pp. 1-30). New York: Atherton.

Burke, K. (1935/1984). Permanence and change: An anatomy of purpose. Berkeley, CA: University of California Press.

Callon, M. (1986). Some elements of a sociology of translation: Domestication of the Scallops and the Fishermen of St Brieuc Bay. In J Law (Ed.), Power, action and belief: A new sociology of knowledge (pp. 196-233). London: Routledge \& Kegan Paul.

Cooren, F. (2010). Action and agency in dialogue: Passion, incarnation, and ventriloquism. Amsterdam/Philadelphia: John Benjamins.

Cooren, F. (2016). Ethics for dummies: Ventriloquism and responsibility. Atlantic Journal of Communication, 24, 17-30.

Cooren, F., \& Sandler, S. (2014). Polyphony, ventriloquism, and constitution: In dialogue with Bakhtin. Communication Theory, 24, 225-244.

Heinelt, G. (1974). Kreative Lehrer=kreative Schüler [Creative teachers=creative students]. Freiburg, Germany: Herder.

Hennessey, B.A., \& Amabile, T.M. (1999). Consensual assessment. In M. Runco \& S. Pritzker (Eds.), Encyclopedia of creativity (pp. 34-36). New York: Academic.

Hennessey, B.A., \& Amabile, T.M. (2010). Creativity. Annual Review of Psychology, 61, 569-598.

James, W. (1912/1976). Essays in radical empiricism. Cambridge, MA: Harvard University Press.

Kaufman, J.C., Lee, J., Baer, J., \& Lee, S. (2007). Captions, consistency, creativity, and the consensual assessment technique: New evidence of reliability. Thinking Skills and Creativity, 2, 96-106.

Kaufman, J.C., Plucker, J.A., \& Baer, J. (2008). Essentials of creativity assessment. Hoboken, NJ: Wiley.

Kuhn, T., \& Burk, N.R. (2014). Spatial design as sociomaterial practice: A (dis)organizing perspective on communicative constitution. In F. Cooren, E. Vaara, A. Langley \& H. Tsoukas (Eds.), Language and communication at work: Discourse, narrativity, and organizing (pp. 147-172). Oxford: Oxford University Press.

Latour, B. (2005). Reassembling the social: An introduction to actor-network theory. New York/Oxford: University Press.

Latour, B. (2013). An inquiry into modes of existence: An anthropology of the moderns. Cambridge: Harvard University Press.

Latour, B., \& Woolgar, S. (1979). Laboratory life: The construction of scientific facts. Beverly Hills: Sage.

Martine, T., Cooren, F., Bénel, A., \& Zacklad, M. (2016). What does really matter in technology adoption and use? A CCO approach. Management Communication Quarterly, 30, 164-187.

Merriam Webster online. Retrieved from http://www.merriam-webster.com/dictionary/novel [last accessed September 20, 2017].

Peirce, C.S. (1897). The logic of relatives. The Monist, 7, 161-217.

Plucker, J.A., \& Makel, M.C. (2010). Assessment of creativity. In J. C. Kaufman \& R. J. Sternberg (Eds.), The Cambridge handbook of creativity (pp. 48-73). New York: Cambridge University Press.

Prelli, L.J., Anderson, F.D., \& Althouse, M.T. (2011). Kenneth Burke on recalcitrance. Rhetoric Society Quarterly, 41, 97-124.

Runco, M.A. (1999). Divergent thinking. In M.A. Runco \& S. Pritzler (Eds.), Encyclopedia of creativity (Vol. 1. Ae-h, pp. 577-582). San Diego: Academic Press.

Runco, M.A. (2008). Commentary: Divergent thinking is not synonymous with creativity. Psychology of Aesthetics, Creativity, and the Arts, 2, 93-96.

Runco, M.A., \& Jaeger, G.J. (2012). The standard definition of creativity. Creativity Research Journal, 24, 92-96.

Simonton, D.K. (1980). Thematic fame and melodic originality: A multivariate computer-content analysis. Journal of Personality, 39, 206-219.

Simonton, D.K. (1999). Origins of genius: Darwinian perspectives on creativity. New York: Oxford University Press.

Stein, M.I. (1953). Creativity and culture. Journal of Psychology, 36, 31-322.

Torrance, E.P. (1974). Torrance tests of creative thinking: Norms-technical manual. Bensenville, IL: Scholastic Testing Service. 
Creativity Assessment and Degrees of Solidity

Vasquez, C. (2013). Spacing organization (or how to be here and there at the same time). In D. Robichaud \& F. Cooren (Eds.), Organization and organizing: Materiality, agency, and discourse (pp. 127-149). New York: Routledge.

Wallach, M.A. (1970). Creativity. In P. Mussen (Ed.), Carmichael's handbook of child psychology (pp. 1211-1272). New York: Wiley,

Thomas Martine, Audencia Business School

François Cooren, Gerald Bartels, Université de Montréal

Correspondence concerning this article should be addressed to Thomas Martine, Audencia Business School, Mediacampus, 41 blvd de la Prairie-au-Duc, 44200 Nantes, France. E-mails: tmartine@audencia.com and th.martine@gmail.com 